07

\title{
Исследование электрофизических свойств коллоидных квантовых точек антимонида индия
}

\author{
() А.И. Михайлов, В.Ф. Кабанов, М.В. Гавриков Ф \\ Саратовский национальный исследовательский государственный университет им. Н.Г. Чернышевского, Саратов, Россия \\ ฯ E-mail: maks.gavrikov.96@gmail.com
}

Поступило в Редакцию 9 декабря 2019г.

В окончательной редакции 9 декабря 2019г.

Принято к публикации 10 января 2020г.

\begin{abstract}
На основе анализа нормированных дифференциальных туннельных вольт-амперных характеристик проведено рассмотрение механизмов токопереноса через квантовые точки антимонида индия. Исследовано туннелирование электронов с учетом дискретного спектра квантовых точек. Проведена оценка положения первых трех уровней их электронного спектра. Показано, что механизм наблюдавшегося тока автоэлектронной эмиссии из пленочной структуры коллоидных квантовых точек антимонида индия удовлетворительно описывается теорией Моргулиса-Стрэттона в диапазоне значений напряженности электрического поля, соответствующем условиям экспериментов.
\end{abstract}

Ключевые слова: квантовые точки, антимонид индия, сканирующая туннельная микроскопия, теория Моргулиса-Стрэттона.

DOI: 10.21883/PJTF.2020.07.49218.18145

Квантовые точки (КТ) на основе антимонида индия $(\mathrm{InSb})$ вызывают особый интерес благодаря уникальным свойствам InSb: малая ширина запрещенной зоны $(\sim 0.18 \mathrm{eV})$, малые эффективные массы электронов $\left(m^{*} \sim 0.013 m_{0}, m_{0}\right.$ - масса свободного электрона), большая длина волны де Бройля электронов (до $55 \mathrm{~nm}$ ) [1-3].

Цель настоящей работы состоит в исследовании и анализе электрофизических свойств пленочной структуры коллоидных квантовых точек антимонида индия.

Коллоидный синтез наночастиц InSb проводился в среде безводного олеиламина с использованием в качестве прекурсоров хлорида индия $\left(\mathrm{InCl}_{3}\right)$ и трис[бис(триметилсилил)амид] сурьмы $\mathrm{Sb}\left[\mathrm{N}\left(\mathrm{Si}-(M e)_{3}\right)_{2}\right]_{3}$ согласно методике [4]. Дополнительная модификация методики заключалась в том, что в качестве прекурсора индия была использована смесь ацетата и хлорида индия в соотношении 4:1. Галогенид в системе необходим для реакции, а добавка ацетата позволила свести к минимуму агрегационные процессы [5].

Слои КТ на стеклянные подложки с проводящим слоем оксида индия-олова (ITO) наносились из коллоидного раствора на поверхности при последующем контролируемом испарении растворителя и контроле параметров слоя оптическими методами.

Полученные образцы были исследованы с помощью просвечивающей электронной микроскопии (ПЭМ) с использованием микроскопа Libra 120; сканирующей туннельной микроскопии (СТM) с использованием сканирующего зондового микроскопа SOLVER NANO; лазерного анализатора размера частиц (Zetasizer Nano ZS); сканирующей электронной микроскопии с использованием автоэмиссионного сканирующего электронного микроскопа MIRA 2 LMU.
Размеры наночастиц (порядка 10-15 nm), оцененные с использованием ПЭМ полученных образцов, представлены на рис. 1. Эти данные позволили рассчитывать на то, что исследуемые наночастицы InSb являются квантово-размерными объектами и должны обладать соответствующими особенностями электрофизических свойств.

Для более полного анализа особенностей электрофизических свойств полученных пленочных образцов с КТ, в частности электронного спектра, в настоящей работе использован метод СТМ. Исследования проводились по известным методикам [6].

Анализ экспериментальных вольт-амперных характеристик (BAX) проводился с помощью нормированных дифференциальных туннельных ВАХ - зависимостей $(d I / d V) /(I / V)$ от напряжения $V$. В ходе исследований рассматривались и анализировались нормированные дифференциальные туннельные ВАХ при отрицательном потенциале смещения на подложке относительно зонда (рис. 2). В этом случае происходит туннелирование электронов из проводящей подложки (электрода ITO) через дискретные уровни КТ в зонд туннельного микроскопа. Этот эффект имеет определенную аналогию с резонансным туннелированием. На нормированных дифференциальных туннельных ВАХ наблюдаются пики, связанные с туннелированием электронов через размерно-квантованные энергетические состояния в КТ (на рис. 2 указаны стрелками).

Для интерпретации экспериментальных результатов BAX в области относительно высоких значений напряженности электрического поля использовались представления об автоэмиссии электронов из металла в вакуум по теории Фаулера-Нордгейма, в соответствии 


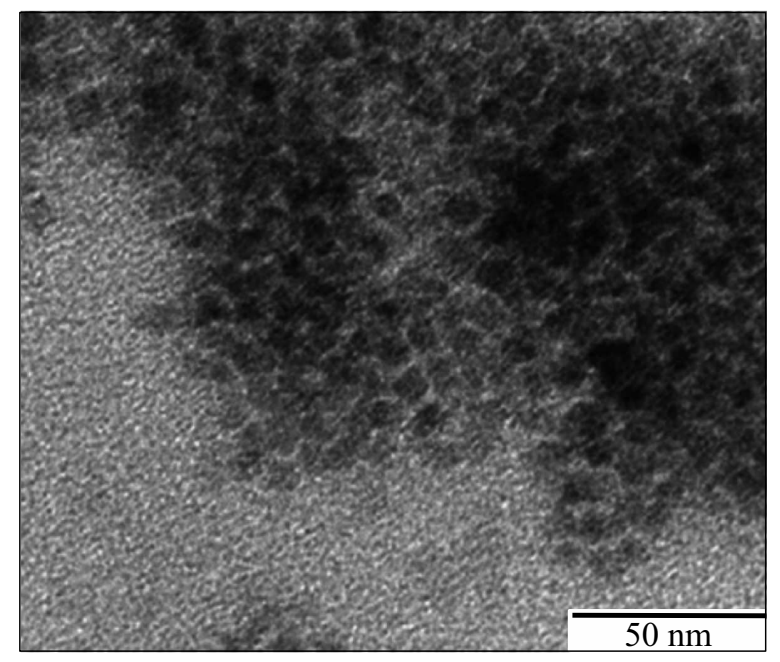

Рис. 1. ПЭМ-изображение квантовых точек InSb.

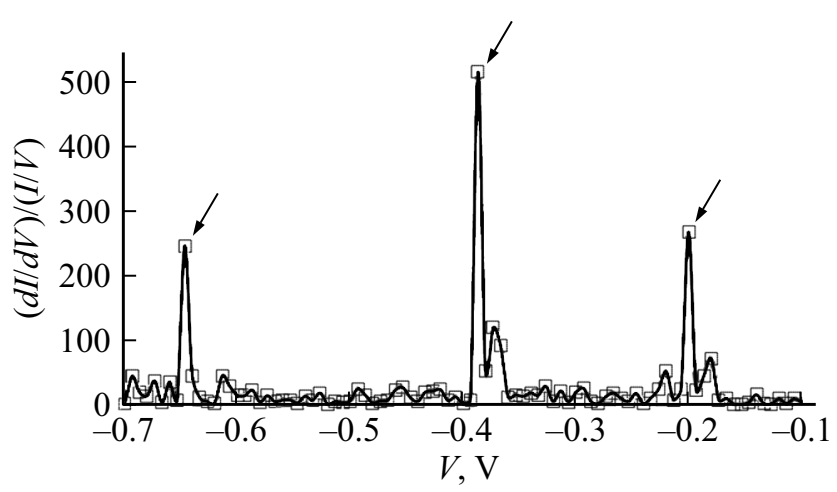

Рис. 2. Типичные нормированные дифференциальные туннельные ВАХ образцов КT InSb.

с которой плотность тока автоэмиссии определяется формулой [7]:

$$
j=\frac{e^{3}}{8 \pi h} \frac{\varepsilon^{2}}{\varphi t^{2}(\varepsilon, \varphi)} \exp \left[-\frac{8 \pi \sqrt{2 m}}{3 h e} \frac{\varphi^{3 / 2}}{\varepsilon} \theta(\varepsilon, \varphi)\right],
$$

и представления об автоэмиссии из полупроводников по теории Моргулиса-Стрэттона [7]:

$$
j_{s}=q n\left(\frac{k T}{2 \pi m_{0}}\right)^{1 / 2} \exp \left[-\frac{8 \pi \sqrt{2 m_{0} A_{s}^{3}}}{3 h q E} \theta\right],
$$

где $m_{0}-$ масса электрона, $\theta-$ значения функции Нордгейма, $\varphi$ и $A_{s}$ - работа выхода электронов из металла и полупроводника соответственно, $E$ - локальная напряженность электрического поля, $t-$ специальная функция, учитывающая влияние на величину тока степени понижения треугольного потенциального барьера [8], $n$ - концентрация электронов, $q$ - модуль заряда электрона.

В соответствии с этими физическими модельными представлениями был проанализирован механизм токопереноса с учетом слоя квантовых точек InSb и проведены некоторые оценочные расчеты характеристик квантово-размерного объекта.

Анализ экспериментальных данных по положению пиков на нормированных дифференциальных туннельных ВАХ для группы образцов (порядка $0.2 \mathrm{~V}$ для первого пика, $0.4 \mathrm{~V}$ для второго пика и $0.6 \mathrm{~V}$ для третьего пика) позволил провести оценку величины линейных размеров КТ по модели кубической формы [2,9] в диапазоне значений $13-18 \mathrm{~nm}$ при погрешности измерений положения пиков по энергии не более $2 k T$. Это соответствует непосредственным измерениям при помощи ПЭМ (рис. 1).

В области относительно сильных электрических полей вблизи поверхности катода (величина напряженности поля более $10^{7} \mathrm{~V} / \mathrm{cm}$ ) были исследованы экспериментальные BAX для эмиссии из платино-иридиевого зонда (отрицательный потенциал на зонде). Линейность зависимости экспериментальных данных в координатах Фаулера-Нордгейма подтверждает доминирование механизма термоэмиссии и позволяет оценить значение функции Нордгейма $\theta$. Оценка величины $\theta$ по группе образцов показала результат 0.6-0.9, что является типичным для металлов.

При положительном смещении на зонде (отрицательный потенциал на подложке) в области относительно высоких значений напряженности поля (более $5 \cdot 10^{6} \mathrm{~V} / \mathrm{cm}$ осуществлялась эмиссия электронов через пленочную

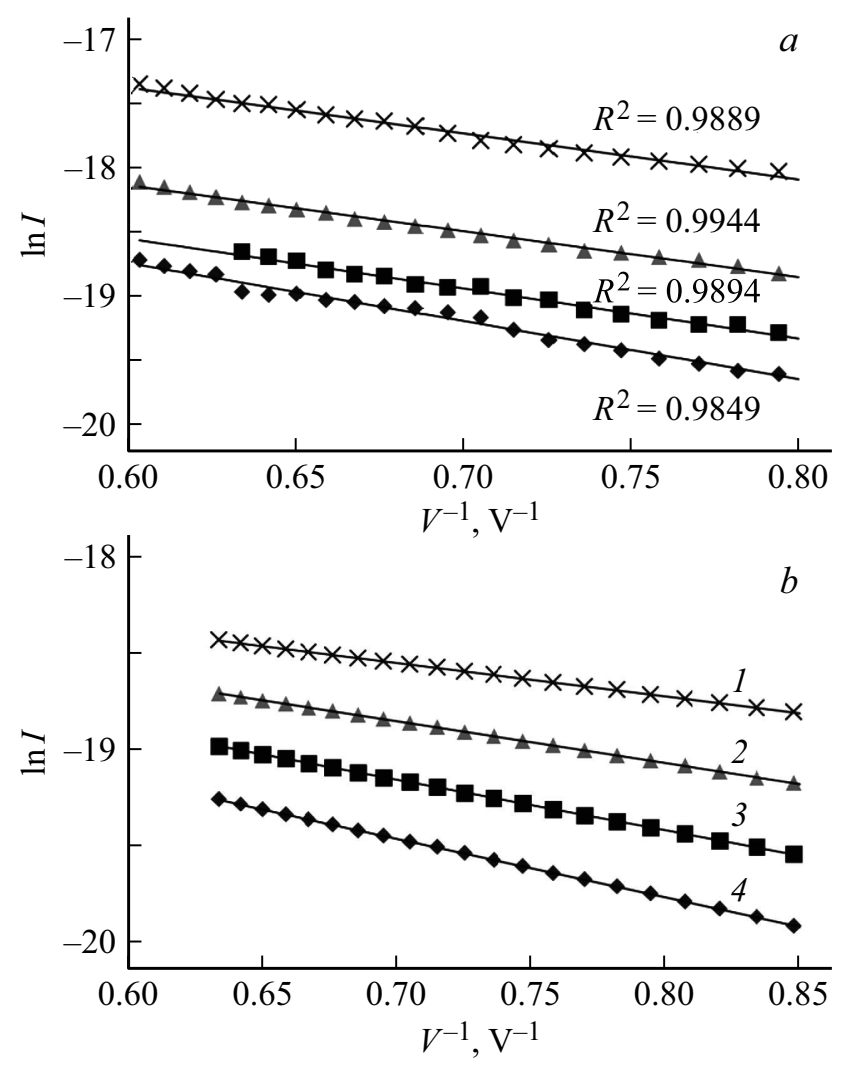

Рис. 3. ВАХ в координатах $\ln I-V^{-1}: a-$ экспериментальные (прямые - линии тренда, $R^{2}-$ величина достоверности аппроксимации); $b-$ расчетные, при $\theta=0.02$ (1), 0.025 (2), $0.03(3), 0.035(4)$. 
структуру коллоидных квантовых точек в зонд. Типичные экспериментальные данные для различных образцов представлены на рис. 3, $a$. Расчетные значения BAX в соответствии с выражением (2) приведены на рис. 3, $b$.

Линейная ВАХ, полученная в координатах $\ln I-V^{-1}$, позволяет сделать вывод, что механизм наблюдавшегося тока автоэлектронной эмиссии из исследуемых образцов удовлетворительно описывается теорией Моргулиса-Стрэттона в диапазоне значений напряженности электрического поля, соответствующем условиям экспериментов. Для проведения численной оценки значений плотности тока локальная напряженность электрического поля определялась как $E=\beta V$, где $V-$ приложенное напряжение, $\beta$ - коэффициент пропорциональности, который зависит от формы и размеров системы катод-анод [10]. Величина работы выхода электронов для КT InSb выбиралась равной $4.9 \mathrm{eV}$, размер зазора между зондом и КТ 1-2 nm. Обработка полученных рассчитанных данных позволила провести оценку величины функции Нордгейма, учитывающей понижение потенциального барьера. Для слоя KT InSb она оказалась порядка $(1.5-3.5) \cdot 10^{-2}$, что существенно меньше, чем значение функции при эмиссии электронов из металла и является характерным значением для эмиссии из полупроводников $[7,10]$.

Таким образом, в работе на основе анализа нормированных дифференциальных туннельных ВАХ проведено рассмотрение механизмов токопереноса из пленочной структуры коллоидных квантовых точек антимонида индия. Показано, что туннелирование электронов осуществляется с учетом дискретного спектра КТ. Анализ нормированных дифференциальных туннельных ВАХ позволил оценить положение первых трех уровней электронного спектра КТ и сделать вывод, что пики на дифференциальных ВАХ адекватно соответствуют расчетным уровням энергетического спектра. Показано, что механизм наблюдавшегося тока автоэлектронной эмиссии из пленочной структуры коллоидных квантовых точек антимонида индия удовлетворительно описывается теорией Моргулиса-Стрэттона в диапазоне значений напряженности электрического поля, соответствующем условиям экспериментов. Проведена оценка величины функции Нордгейма для КТ InSb, которая оказалась порядка $(1.5-3.5) \cdot 10^{-2}$, что существенно меньше, чем значение функции при эмиссии электронов из металла $(0.7-0.9)$

\section{Финансирование работы}

Исследование выполнено при финансовой поддержке Российского фонда фундаментальных исследований в рамках научного проекта № 19-07-00087.

\section{Конфликт интересов}

Авторы заявляют, что у них нет конфликта интересов.

\section{Список литературы}

[1] Abautret J., Perez J.P., Evirgen A., Rothman J., Cordat A., Christol P. // J. Appl. Phys. 2015. V. 117. N 24. P. 244502 $(1-6)$.

[2] Михайлов А.И., Кабанов В.Ф., Горбачев И.А., Глуховской Е.Г. // ФТП. 2018. Т. 52. В. 6. С. 603-607.

[3] Mikhailov A.I., Kabanov V.F., Zhukov N.D., Glukhovskoy E.G. // Nanosystems: Physics, Chemistry, Mathematics. 2017. V. 8. N 5. P. 596-599.

[4] Liu W., Chang A.Y., Schaller R.D., Talapin D.V. // J. Am. Chem. Soc. 2012. V. 134. N 50. P. 20258-20261.

[5] Кабанов В.Ф., Михайлов А.И., Гавриков М.В., Крыльский Д.В. Свойства квантовых точек InSb, полученных методами коллоидного синтеза и химического травления // Микро- и нанотехнологии в электронике. Материалы XI Междунар. науч.-техн. конф. Нальчик: Кабард.-Балкар. ун-т, 2019. С. 116-120.

[6] Mikhailov A.I., Kabanov V.F., Glukhovskoy E.G., Shishkin M.I., Gavrikov M.V. // Nanosystems: Physics, Chemistry, Mathematics. 2018. V. 9. N 4. P. 464-467.

[7] Егоров Н.В., Шешин Е.П. Автоэлектронная эмиссия. Принципы и приборы. М.: Интеллект, 2011. 704 с.

[8] Кузьменко А.П., Кузько А.Е., Тимаков Д.И. // ЖТФ. 2013. T. 83. B. 2. C. $91-96$.

[9] Драгунов В.П., Неизвестный И.Г., Гридчин В.А. Основы наноэлектроники. М.: Логос, 2006. 496 с.

[10] Михайлов А.И., Кабанов В.Ф., Жуков Н.Д. // Письма в ЖТФ. 2015. Т. 41. В. 12. С. 8-14. 